\title{
Commentary: Cardinal principles
}

\author{
Jonathan M. Chen, MD
}

One of the most onerous and common cardiac anomalies is the persistence of a left superior vena cava (LSVC), affecting $\sim 0.3 \%$ of the population and irritating congenital surgeons worldwide for time eternal. Originally a component of the ducts of Cuvier (common cardinal veins), which undergoes involution (thereby contributing to the vestigial fold of Marshall), its persistence-especially if unexpected - can considerably complicate an otherwise enjoyable orthotopic heart transplant. In this setting, the management of the LSVC will largely depend on the presence or absence of a right SVC and/or an innominate "bridging" vein. For those without a bridging vein, incorporation of the systemic venous drainage from the left upper body will be required, for which any number of clever techniques have been proposed depending on the continuity of the LSVC with an intact coronary sinus (in contrast to entrance into the dome of the left-sided atrium or previous usage for a cavopulmonary anastomosis). ${ }^{1-4}$

In this issue of JTCVS Techniques, de Magalhães Ferraz and colleagues ${ }^{5}$ have presented a rare instance in which an innominate vein persisted but all the upper body (right and left) systemic veins were draining through a persistent LSVC to the coronary sinus (without situs inversus totalis - the inferior cava was right sided) and have proposed a clever solution to "bridge the gap" to the normal situs donor heart. ${ }^{5}$ Their results, as illustrated in the intraoperative and 3-dimensional reconstructions, are enviably unobstructed, albeit quite similar to the techniques reported

From the Department of Cardiothoracic Surgery, Children's Hospital of Philadelphia, Philadelphia, Pa.

Disclosures: The author reported no conflicts of interest.

The Journal policy requires editors and reviewers to disclose conflicts of interest and to decline handling or reviewing manuscripts for which they may have a conflict of interest. The editors and reviewers of this article have no conflicts of interest.

Received for publication June 13, 2020; revisions received June 13, 2020; accepted for publication June 17, 2020; available ahead of print June 24, 2020.

Address for reprints: Jonathan M. Chen, MD, Department of Cardiothoracic Surgery, Children's Hospital of Philadelphia, 3401 Civic Center Boulevard, Suite 8574, Philadelphia, PA 19104 (E-mail: chenj14@email.chop.edu).

JTCVS Techniques 2020;3:230-1

2666-2507

Copyright (C) 2020 The Authors. Published by Elsevier Inc. on behalf of The American Association for Thoracic Surgery. This is an open access article under the CC BY-NCND license (http://creativecommons.org/licenses/by-nc-nd/4.0/).

https://doi.org/10.1016/j.xjtc.2020.06.033

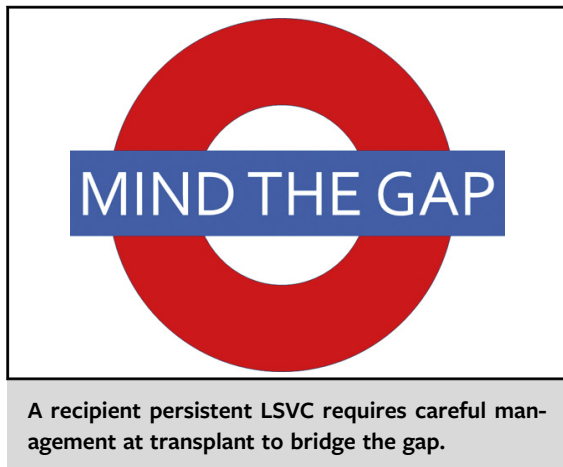

CENTRAL MESSAGE

Heart transplantation in the setting of a recipient left superior vena cava can be addressed with many techniques, all aimed at providing unobstructed systemic venous drainage to the contralateral donor superior vena cava once in situ.

previously. ${ }^{6,7}$ As they noted, although a common practice in the absence of a bridging vein has been to baffle the left-sided systemic venous return at transplantation with a donor innominate vein, not infrequently this can lead to obstruction if placed either in front of, or behind, the aortic anastomosis (even despite intentional adjustments in the size of the neo-ascending aorta).

However, although they appropriately referenced inferior long-term survival with biatrial versus bicaval anastomoses in transplantation, the exact reasons for this discrepancy have not historically been well delineated. A simpler technical solution in this particular case could have been to allow the LSVC to coronary sinus drainage to remain intact at the recipient cardiectomy, thereby providing a known unobstructed pathway for one third of the systemic venous return; incorporating this into the recipient inferior vena cava cuff (or performing a "true" biatrial anastomosis) is straightforward. Instead, in choosing to pursue a bicaval connection, one must "mind the gap" between the very posterior LSVC and the donor rightsided SVC to prevent obstruction and potential thrombosis and all the sequelae that could follow.

To be sure, any and all techniques shared to add to the armamentarium are welcome. The key is to provide 
unobstructed systemic venous drainage and avoid the cardinal sin (to the cardinal vein) of distortion or obstruction. As the authors noted, forewarned is forearmed-preoperative preparation for such congenital anomalies can transform an unexpected 5-alarm fire into a pleasing creative exercise.

\section{References}

1. Huddleston CB, Richey S, Fiore AC. Heart transplantation for congenital heart disease. Op Tech Thorac Cardiovasc Surg. 2019;24:103-20.

2. Handa K, Hata H, Toda K, Miyagawa S, Yoshikawa Y, Yoshioka D, et al. Orthotopic heart transplantation with reconstruction of persistent left superior vena cava. Surg Case Rep. 2020;6:71.
3. Reyes KM, Gupta D, Fricker FJ, Cook S, Bleiweiss MS. Heart transplant in a patient with isolated left superior vena cava by atrial appendage rotation. Ann Thorac Surg. 2018;105:e279-81

4. Neragi-Miandoab S, Baran D, Godelman A, Goldstein DJ. Orthotopic heart transplantation in patients with persistent left superior vena cava: bicaval and biatrial techniques. Ann Thorac Surg. 2014;97:85-7.

5. de Magalhães Ferraz DL, Walter FR, Carneiro da Cunha CB. Bicaval orthotopic heart transplantation in a patient with persistent left superior vena cava. J Thorac Cardiovasc Surg Tech. 2020;3:227-9.

6. Tanaka A, Lonchyna V, Ota T. Persistent left superior vena cava and cardiac transplantation: anterior rerouting with anastomosis to the right atrium. J Heart Lung Transplant. 2015;34:1215-6.

7. Lee JH, Park E, Lee W, Cho H, Kim K, Hwang HY. Heart transplantation in a patient with persistent left superior vena cava. Korean J Thorac Cardiovasc Surg. 2014; $47: 533-5$. 